\title{
AS POLÍTICAS EDUCACIONAIS NO PERÍODO DE 1956 A 1979, NO MUNICÍPIO DE SÃO JOSÉ DOS PINHAIS: A ESCOLA NORMAL COLEGIAL ESTADUAL HENRIQUE PESTALOZZI
}

\section{Las políticas educacionales en el período de 1956 a 1979,en el ,municipio de San Jose de Pinhais: La Escuela Normal Provinciall Henrique Pestalozzi}

Maria Lúcia Bassa Zem ${ }^{1}$

\section{Resumo}

Este trabalho tem como tema "As políticas educacionais no contexto da Escola Normal, no peńodo de 1956a 1979, no município de São José dos Pinhais". A escola pesquisada é Escola Nomal Colegial Estadual Hennique Pestalozzi. Foi criada em 1954 e iniciou seu funcionamento em 1956, encerrando suas atividades no ano de 1979. Durante esse período, ela esteve sob a vigência da Lei Orgânica do Ensino Normal, de 1946 e da Lei de Diretrizes e Bases Lei 4024/61. Nesse estudo, se propôs investigar o problema assim sintetizado: como a Escola Normal em São José dos Pinhais, no peńodo de 1971 a 1979, funcionou e foi se adequando aos ditames da nova legislação, considerando suas reais condições de trabalho? O principal objetivo deste estudo foi analisar como se configuraram as políticas educacionais no contexto da Escola Nomal, no peńodo de 1956 a 1979, relacionadas com o cenánio estadual e nacional. Para chegar a essa análise, delinearam-se os seguintes objetivos específicos: identificar os fatores que contribuíram para a criação e o funcionamento da Escola Nomal no Município de São José dos Pinhais no período de 1956 a 1979; compreender como as legislações, leis específicas relativas à formação de professores interferiram (ou não) no funcionamento da Escola; identificar de que modo a política mais ampla (não educacional) foi ou não determinante para a criação e o funcionamento da Escola e verificar as relações estabelecidas entre a Escola Normal e as demais instituições sociais do Município. Palavras-chave: Escola Normal; Legislação; Sociedade; Política; Formação de professores.

Mestre em Educação, professora da Área de Educação da Pontifícia Universidade Católica do Paraná, Rua Imaculada Conceição, no 1155, Prado Velho, CEP. 80215-901 - Curitiba/PR

E-mail: bzem@bol.com.br 


\section{Resumen}

Este trabajo tiene como asunto "Las políticas educacionales en el contexto de La Escuela Normal, en el periodo de 1956 hasta 1979, en el município de São José dos Pinhais. La escuela estudiada fue creada en 1954 y instalada en 1956, y funciono hasta el final del año 1979. Durante ese periodo ella estuvo bajo las normas de la ley Orgânica de la Enseñanza Normal, de 1946 y de la Ley de Directrizes y Bases Ley 4024/61. En este estúdio se propone investigar el problema de: ¿como la Escuela Normal en São José dos Pinhais, en el periodo de 1971 hasta 1979, funciono y fue adecuandose a los ditames de la nueva legislacion, considerando sus reales condiciones de trabajo? La principal finalidad de el estudio fue analizar como configuraronse las politicas educacionales en el contexto de la Escuela Normal, en el periodo de 1956 hasta 1979, relacionada con el escenario estadual e nacional. Para llegar a esa analise delinearonse los seguintes objetivos específicos: identificar los factores que contribulleron para la creacion y el funcionamento de la Escuela Normal en el Municipio de São José dos Pinhais en el periodo de 1956 hasta 1979; compreender como las legislaciones, leyes especificas relactivas a la formacion de professores interferiron (o no) en el funcionamento de la Escuela; identificar de cual modo la politica mas ancha (no educacional) fue o no determinante para la creacion y funcionamento de la Escuela y verificar las relaciones estabelecidas entre la Escuela Normal y las demás instituiciones sociales de el Municipio.

Palabras-llave: Escuela normal; Legislacion; Sociedad, Politica.

Ao pretender trabalhar as políticas educacionais no período de 1956 a 1979 no Município de São José dos Pinhais: a Escola Normal Colegial Estadual Henrique Pestalozzi, buscou-se investigar o seguinte problema: como a Escola Normal C. E. Henrique Pestalozzi, no período de 1971 a 1979, funcionou e foi se adequando aos ditames da nova legislação, considerando suas reais condições de trabalho?

A pesquisa teve como objetivo principal analisar como se configuraram as políticas educacionais no contexto da Escola Normal Henrique Pestalozzi, no Município de São José dos Pinhais, no período de 1956 a 1979. Para esta análise foram delineados objetivos específicos assim sintetizados: identificar os fatores que contribuíram para a criação e o funcionamento da Escola Normal no Município de São José dos Pinhais no período de 1956 a 1979; compreender como as legislações, leis específicas de formação de professores interferiram (ou não) no funcionamento da Escola Normal no Município; identificar de que modo a ação política mais ampla (não educacional) foi ou não determinante para a criação e o funcionamento da Escola e verificar as relações estabelecidas entre a Escola Normal e as demais instituições sociais do Município.

Para buscar respostas às questões levantadas foi necessário realizar uma revisão bibliográfica acerca da formação de professores e sobre o contex- 
to do Município de São José dos Pinhais no período nos aspectos: econômico, político, cultural e educacional, relacionado ao conjunto do Paraná e do Brasil. A busca da legislação permitiu o entendimento do processo de conformação oficial.

A pesquisa utilizou informações contidas em documentos oficiais, tais como: Leis, Decretos, Resoluções, Portarias. Documentos da Escola: relatórios finais de notas de alunos, atas de exames, correspondência recebida e expedida à Secretaria de Educação. Tais fontes foram fundamentais para 0 estudo. As fontes documentais da Escola pesquisada foram encontradas no Colégio Estadual Costa Viana que guarda o referido acervo.

A coleção da Revista Brasileira de Estudos Pedagógicos, editada pelo Instituto Nacional de Estudos e Pesquisas Educacionais, na Biblioteca Central da Universidade Federal do Paraná, possibilitou o contato com textos da época, sobre o tema, principalmente de Anísio Teixeira e Lourenço Filho.

A Sessão Paranaense da Biblioteca Pública do Paraná permitiu o acesso aos Diários Oficiais do Estado do Paraná.

O Museu "Atílio Rocco" de São José dos Pinhais possui, em seu acervo, os jornais do Município, desde 1950, os quais foram importantes na complementação dos dados obtidos no único livro sobre o Município que trata da organização da sociedade local no período: São José dos Pinhais - a Trajetória de Uma Cidade, escrito por Colnaghi, Magalhães Filho e Brephol de Magalhães, (1992).

Foram utilizadas outras fontes, como: revistas, fôlderes, encartes, divulgados pela Prefeitura Municipal de São José dos Pinhais.

As consultas ao Núcleo Regional da área Metropolitana Sul - Subsede São José dos Pinhais, foram importantes para o acesso a dados da situação educacional do município no período.

Foram ainda, realizadas cinco entrevistas: com duas ex-diretoras, uma ex-professora, uma ex-secretária e uma ex-aluna da Escola Normal Henrique Pestalozzi, as quais contribuíram, no sentido de apontar a existência de documentos e outros materiais que ainda não haviam sido localizados.

\section{A Escola Normal Colegial Estadual Henrique Pestalozzi}

A Escola Normal Colegial Estadual Henrique Pestalozzi, objeto de estudo deste trabalho, esteve em funcionamento no município de São José dos Pinhais de 1956 a 1979.

Foi criada pela Lei 1054 de 21 de janeiro de 1954, com a denominação de Escola Normal Secundária de São José dos Pinhais, cujo ato oficial foi publicado no Diário Oficial do Estado do Paraná de no 278 de 20 de fevereiro de 1954. 
Após as entrevistas com pessoas ligadas à Escola, conseguiram-se informações de que, realmente a Escola Normal em São José só iniciou seu funcionamento em março de 1956, cuja aula inaugural aconteceu em 10 de abril de 1956; portanto, foi instalada dois anos após sua criação. Buscando os motivos pelos quais este fato havia ocorrido, chegou-se a algumas hipóteses.

A primeira refere-se à questão da legislação. Nesse momento, década de 50, estava em vigor a Lei Orgânica do Ensino Normal, que vigia desde 1946, na qual o Parágrafo Único do Art. 42 determinava: "não poderá ser concedido mandato para curso de segundo ciclo do ensino normal, senão a estabelecimento que já possua ginásio oficialmente reconhecido". (Art. 42. Lei Orgânica do Ensino Normal, 1946). Em 1954, data da criação da Escola Normal em São José, o município possuía um ginásio, porém de caráter particular, o qual foi estadualizado somente em 28 de janeiro de 1956 pelo Decreto n.․ 20.868 do Governo do Estado do Paraná. A segunda hipótese sobre 0 intervalo de dois anos entre a criação e a instalação e funcionamento da Escola Normal pode ser atribuído ao momento político, oportuno, em que São José, em 1954, havia elegido dois representantes para a Assembléia Legislativa, um dos quais pelo Partido Social Democrático (PSD), partido da situação do Governo do Estado. O jornal Correio de São José relatou atividades parlamentares do Deputado Ernesto Moro, em que cita dentre elas a autoria de: "Projeto de Lei, criando uma Escola Normal Secundária na cidade de São José dos Pinhais, e abrindo crédito especial de CR\$250.000, destinado a ocorrer as despesas decorrentes com a execução da presente Lei. Promulgado em 21/1/ 54" (JORNAL CORREIO DE SÃO JOSÉ, 23 ago. 1954). A terceira provável explicação para o fato do não funcionamento da escola poderia estar na baixa demanda de alunos, pois a primeira turma, que iniciou o Curso Normal em 1956, contou com 11 alunas matriculadas, das quais apenas 10 se formaram, conforme Relatório Anual de Notas da Escola Normal. (1958). A professora Filomena Cozetti Galante, primeira Diretora da Escola Normal, confirma com o seguinte relato: "Precisava para poder funcionar, contar com 12 alunas(...) e aí então comecei a correr e a gente conseguiu o número de alunas necessárias.(...) Tanto que a Jaci, minha irmã, que já fazia Contabilidade no Colégio São José se matriculou para que concorresse com mais uma aluna".

É provável que a Escola Normal tenha obtido autorização para funcionar, mesmo sem o número de alunas exigido, por interferência do Professor Narciso Mendes, que naquele ano era Chefe de Gabinete da Secretaria de Educação e Cultura. O Professor Narciso Mendes residia no Município de São José, onde também exercia o mandato de vereador, e defendia na Câmara Municipal a causa da Educação são-joseense. Na ocasião da instalação da Escola Normal de São José dos Pinhais, o citado vereador solicitara ao plenário: "fosse enviado um telegrama de agradecimento ao Excelentíssimo Senhor 
Governador do Estado, pela instalação da Escola Normal de São José dos Pinhais" (Ata da 5. ${ }^{a}$ sessão da 1. ${ }^{a}$ Reunião Ordinária do ano de 1956, de 21/05/ 1956). No depoimento da professora Alice Cordeiro, quando perguntada sobre o fato da escola ter sido uma solicitação da comunidade, a professora relatou: "o povo realmente queria, quem não quer uma escola. Mas a finalidade toda foi política, mas não havia e precisava" (Entrevista Prof.? Alice, 2004). Nesse período, segundo Miguel (1997, p. 120) "através do INEP, o governo procurava dar ao ensino primário, a base física do sistema escolar com a construção de 7.000 escolas rurais. Mas afirmava também que, para tal projeto, necessitava 'procurar a base pedagógica'". Essa base pedagógica seria dada pelos Cursos Normais que formavam os professores primários. Pode ter sido esta política do governo federal outro motivo da criação da Escola Normal em São José.

No entanto, São José, no ano de 1956, esteve à margem de todo o desenvolvimento que ocorria na Capital e no restante do Paraná, era um Município com estrutura basicamente agrícola, com a instalação de algumas serrarias em seu território e que naquele momento não tinha urgente necessidade de uma Escola Normal para todos, a não ser para atender a uma elite, filhos de imigrantes que ascenderam socialmente, que já estudavam em Curitiba, embora com dificuldades de locomoção, devido à precariedade das estradas e escassez de horários dos ônibus.

Em nível federal, a política do governo estava centrada no desenvolvimento industrial no País, no Paraná o setor industrial teve sua expansão apenas a partir de 1961, quando Ney Braga, assumindo o governo do Estado, teve a preocupação de atender às novas exigências que se apresentavam no que diz respeito à industrialização em conformidade com a política de Juscelino Kubistchek. Era preciso racionalizar a máquina administrativa e dotá-la de eficiência para atender tais exigências. Os recursos do Estado deveriam ser destinados ao financiamento de investimentos públicos no setor de energia elétrica, construção de rodovias e de empreendimentos de incentivo à industrialização pelo governo paranaense.

Para o processo de modernização do Estado via industrialização, era necessário assegurar a produção energética pelos seus próprios sistemas. A Companhia Paranaense de Energia Elétrica (COPEL), em 1970, produzia 467.000 kW com a inclusão da Usina Mourão I, Salto Grande, Julio de Mesquita Filho e a Central Hidrelétrica de Capivari-Cachoeira. O governo passou a investir na política de eletrificação rural. No setor rodoviário, foi fundamental a Rodovia do Café, entre Paranaguá e Paranavaí, pois segundo o governador, representava a via básica da economia paranaense. A maioria da produção do Paraná era escoada pelo Porto de Santos, o que prejudicava a arrecadação do Estado. 
O fenômeno da industrialização no Paraná alterou em parte a imagem do Estado, não era mais uma região meramente agrícola, mas industrial, de serviços, de lazer tipicamente urbano, nos cinemas, teatros e hábitos de consumo diversificados.

São José dos Pinhais, como conseqüência dessa política, foi beneficiado com a ampliação da rede elétrica para as localidades que não a possuíam, e pela construção da BR 277 que liga Curitiba a Paranaguá. Isso possibilitou, mais tarde, a partir de 1976, que indústrias viessem se instalar no Município, que pode então, inserir-se no processo industrial antes concentrado em Curitiba.

\section{A Escola Normal Colegial Estadual Henrique Pestalozzi: Organiza- ção e Funcionamento}

Retomando a Escola Normal, dos 23 anos de funcionamento como instituição de ensino, esta escola formou alunos de São José dos Pinhais, mas também de Curitiba, principalmente residentes nos bairros de Boqueirão e Uberaba, alunos de Quatro Barras, Agudos do Sul, Tijucas do Sul e de Mandirituba.

A Escola Normal Henrique Pestalozzi funcionou de 1956 a 1962, sob a égide da Lei Orgânica do Ensino Normal, de 1946. A partir de 1962 até 0 encerramento de suas atividades em 1979, em conformidade com a Lei de Diretrizes e Bases, Lei 4024/61.

A Lei 5692/ 71 de agosto de 1971 foi implantada no Município, de 5. ${ }^{\mathrm{a}}$ a 8. ${ }^{\text {a }}$ série, a partir de 1973 , de forma gradativa como previa a própria Lei. Teoricamente em 1977, deveria ter sido implantada no Ensino de 2. ${ }^{\circ} \mathrm{Grau}$, mas isso não aconteceu. São José dos Pinhais participou da Expansão III no plano de implantação da Reforma de Ensino de 2. ${ }^{\circ} \mathrm{Grau}$. As fontes documentais da Escola apresentam o pedido de implantação da habilitação Magistério no ano de 1977, pelo ofício n. ${ }^{\circ} 153 / 77$ de $1 .^{\circ}$ de agosto de 1977 , assinado pelo Inspetor Regional de Ensino.

Procedida a verificação das condições para o funcionamento, a Comissão de Verificação deu parecer favorável para que essa ocorresse. Em 1978, implantou-se no Colégio Estadual Costa Viana as Habilitações: Magistério e Técnico em Contabilidade e em 1979 a Habilitação Básica em Saúde. A Lei 5692 era exigente em relação aos recursos físicos e materiais. Para cada habilitação havia um rol de materiais mínimos necessários para serem utilizados e era exigido: sala para biblioteca, salas para laboratórios e materiais de Química, Física e Biologia. O Colégio Costa Viana, na ocasião, possuía 7 salas de aula, as quais seriam utilizadas para as turmas de $1 .^{\circ} \mathrm{grau}$, e para as turmas das habilitações implantadas. A Biblioteca possuía uma sala com a metragem mí- 
nima exigida e o acervo mínimo necessário. Não havia salas especiais para 0 treinamento das habilitações programadas, tampouco sala para os laboratórios de Química, Física e Biologia. O laboratório de Ciências era incompleto, necessitando equipamentos para as habilitações solicitadas (Relatório da Comissão de Verificação Prévia). Mesmo com a deficiência de espaço físico e recursos materiais, em 1978 o PARECER 082/78 do Conselho Estadual de Educação aprovou o Projeto de Implantação do ensino de $2 .{ }^{\circ} \mathrm{Grau}$ com as habilitações de Magistério e Técnico em Contabilidade a iniciar-se em 1978 e Básica em Saúde, com início previsto para 1979. Nesse mesmo ano a Escola Normal continuou funcionando pela antiga Lei 4024/61, ainda no "Casarão", com a última série pela Lei 4024/61.

Em 1979, o Decreto n. ${ }^{\circ} 6.337$ de 21 de fevereiro de 1979, do Governo do Estado do Paraná autorizou o funcionamento do Complexo Escolar Iguaçu - Ensino de $1 .^{\circ}$ e 2..$^{\circ}$ Graus, no município de São José dos Pinhais. Este complexo escolar resultou da reorganização do Ginásio Estadual Costa Viana, Escola Normal Colegial Estadual Henrique Pestalozzi, Colégio Comercial Estadual Roque Vernalha, Grupo Escolar Afonso Pena e Escola de Aplicação Olavo Bilac.

O Ginásio Estadual Costa Viana, a Escola Normal Colegial Estadual Henrique Pestalozzi e o Colégio Comercial Estadual Roque Vernalha passaram a constituir-se em um único estabelecimento, sob a denominação de Colégio Estadual Costa Viana - Ensino de 1. ${ }^{\circ}$ e $2 .^{\circ}$ Graus (Art. 2. ${ }^{\circ}$, Decreto N. ${ }^{\circ}$ 6.337).

Esse decreto, no Art. $4^{\circ}$ prescrevia: "Em decorrência do disposto no Artigo $1 .^{\circ}$, os estabelecimentos manterão em regime de extinção gradativa 0 funcionamento das séries referentes aos cursos regidos pela Lei de Diretrizes e Bases da Educação Nacional, n. ${ }^{\circ}$ 4.024, de 20 de dezembro de 1961 (Decreto n. ${ }^{\circ}$ 6.337).

A Escola Normal Colegial Estadual Henrique Pestalozzi funcionou adequando-se às orientações da legislação federal e estadual.

Do início de seu funcionamento até 1962, essa escola esteve pautada nas orientações da Lei Orgânica do Ensino Normal de 2 de janeiro de 1946.

O Curso era ofertado em 3 séries anuais. O programa do curso contemplava as disciplinas propostas no Art. 7. ${ }^{\circ}$ da Lei Orgânica do Ensino Normal, com exceção da disciplina de Estudos Brasileiros e Paranaenses ofertada na $1 .^{\mathrm{a}}$ e $2 .^{\mathrm{a}}$ séries, a qual não estava prevista na Lei. Essa abertura era dada no Art. 46 da referida Lei, que prescrevia: "A legislação de cada unidade federada poderá acrescer disciplinas à seriação indicada nos artigos $7 .^{\circ}, 8^{\circ}$ e $9 .^{\circ}$, ou desdobrá-las, para maior eficiência do ensino (Art. 46, Lei Orgânica do Ensino Normal, 1946).

O Ensino Religioso também fazia parte do programa de disciplinas da Escola. As aulas eram ministradas pelo Padre Pedro Fuss, o vigário da 
Paróquia de São José. Como previa a Lei, essa disciplina era trabalhada, porém não poderia constituir objeto de obrigação de mestres ou professores, nem de freqüência compulsória por parte dos alunos.

A Escola normal mantinha uma escola primária anexa, conforme determinava o Art. 47 da Lei Orgânica do Ensino Normal. "Todos os estabelecimentos de ensino normal manterão escolas primárias anexas para demonstração e prática de ensino" (Art. 47, Lei Orgânica do Ensino Normal, 1946).

A Escola Normal Henrique Pestalozzi funcionou adequando-se às orientações da legislação federal, estadual e especificamente do Serviço de Ensino Normal (SNE) da Secretaria de Educação e Cultura. Segundo registro encontrado na documentação da Escola, em livro de Ofícios Circulares, Avisos e Instruções dos anos de 1959 e 1960, esse Serviço compunha-se de um setor, o Setor de Assistência Técnica (SAT), o qual tinha a incumbência de manter as Escolas Normais informadas sobre as determinações concernentes a esse nível de ensino e esclarecer dúvidas a respeito do trabalho pedagógico na escola.

Os assuntos abordados nos ofícios circulares, nos avisos e instruções eram os mais variados: determinação das comemorações das datas cívicas na escola, agradecimentos aos professores por comparecimento às reuniões no início do período letivo, repasse do conteúdo das Resoluções da Secretaria de Educação e evidenciou-se a preocupação do Serviço de Ensino Normal com a atualização dos professores, pelas convocações insistentes para que os mesmos participassem nas reuniões realizadas pelo Setor no início do ano letivo. Outra evidência é o teor do Ofício Circular n. ${ }^{\circ} 14$ de 23 de agosto de 1956, o qual solicita que:

a) sejam feitas reuniões mensais (em seguida à ultima aula) a fim de que todos os professores possam conhecer e interpretar os artigos que regem a Regulamentação dos Cursos Normais;

b) estas reuniões devem ter um dia fixado a fim de não causar atrapalhos ao Corpo Docente;

c) devem ter caráter efetivo, visando também o aproveitamento dos alunos, os programas, matéria lecionada, dificuldades encontradas e outros assuntos que se relacionem com a Escola;

d) apresentação de sugestões para melhor funcionamento do Curso;

e) a Direção deverá anotar to dos os assuntos abordados em um livro especial que deverá ser assinado por todos que comparecerem às reuniões.

Esse encaminhamento dado às Escolas Normais pelo Serviço de Ensino Normal, parece ter sido influenciado também pelas idéias de Pilotto, quando este segundo Miguel (1997, p.74) "idealizou 'o plano de formação do magistério primário', plano este que foi colocado em prática, e que orientava o trabalho na Escola de Professores de Curitiba", a partir de 1946. 
Uma das finalidades da Escola Normal no plano de Pilotto era que a escola deveria "ser um centro de cultura pedagógica, compreendendo-se, aqui, mais particularmente a investigação filosófica e a investigação experimental relativa aos problemas ligados ao fenômeno da Educação" (MIGUEL, p.74-75).

Verificou-se também a ênfase aos deveres cívicos na Escola, procurando despertar nos alunos o amor à Pátria e o dever da sociabilidade. As comemorações das datas cívicas a serem realizadas na Escola eram determinadas pelo Serviço de Ensino Normal, onde este sugeria as principais datas a serem comemoradas durante 0 ano e a utilização do último horário das aulas para que estas se efetivassem. De acordo com a Circular n.․ 20/59 e 3/60, as datas a ser comemoradas eram:

\section{$1 .^{\circ}$ de março - aula inaugural \\ 14 de abril - Dia Pan Americano \\ 21 de abril - Tiradentes \\ 1. ${ }^{\circ}$ de maio - Dia do Trabalho \\ 2. ${ }^{\circ}$ Domingo de Maio - Dia das Mães}

7 de setembro - Independência do Brasil

Outubro - Semana da Criança

15 de Novembro - Proclamação da República

Dia da instalação da Escola, Semana da Boa Leitura e Dia do Livro.

Ainda devem ser comemoradas as datas do Município.

De cada comemoração deverá ser enviado um relatónio para o SEN. (SEN Circular n. $\stackrel{0}{20 / 59}$ e 3/60).

O desenvolvimento do espírito cívico e amor à pátria estava delineado na Lei Orgânica do Ensino Normal no Art. 13, alínea b, que previa: " a educação moral e cívica não deverá constar de programa específico, mas resultará do espíito e da execução de todo o ensino" (Art. 13, Lei Orgânica do Ensino Normal, 1946).

A avaliação realizada pela Escola evidenciou a adequação à Lei Orgânica do Ensino Normal. Esta se constituía de critérios rigorosos. Era realizada desde 0 ingresso no curso, onde era feita uma seleção por meio de provas (exame de admissão) que era exigência, conforme Art. 20 dessa Lei. "Habilitação nos exames de admissão" (Art. 20, Lei Orgânica do Ensino Normal, 1946).

A Escola Normal C. E. Henrique Pestalozzi participou do PABAEE, Programa Americano Brasileiro de Assistência Ao Ensino Elementar, enviando como bolsista a professora Maria Carolina Delay, a qual foi para os Estados Unidos. O objetivo do PABAEE naquele momento era realizar a instrução de professores das Escolas Normais em relação às Metodologias de Ensino, e da Psicologia para estes serem multiplicadores das inovações trazidas dos Estados Unidos nos cursos em que atuavam nas Escolas Normais. 
Pode-se dizer que a Escola Normal Henrique Pestalozzi em São José dos Pinhais, durante o seu funcionamento nos anos de 1956 a 1979, esteve sob o jugo das políticas oficiais tanto as de caráter nacional como as de caráter estadual, no entanto, não se inseriu no contexto que se imprimiu nos anos 70, retratado na Lei 5692/71. A Escola continuou seu trabalho atuando conforme a Lei 4024/61até encerrar suas atividades em 1979.

Nos anos iniciais de seu funcionamento, principalmente 1959 e 1960, de cujo período foi possível resgatar documentos da própria escola, pode-se perceber pela análise dos mesmos que a escola mesclava seus procedimentos de ação. Em algumas ações atuava de forma tradicional, em outras deixou transparecer uma tendência vinculada à Pedagogia da Escola Nova e ainda em outras as ações relacionadas à Pedagogia Tecnicista, adequando-se ao contexto e as mudanças das políticas propostas.

São encontradas evidências explicativas desta afirmação nos fatos relatados a seguir. As questões mais ligadas à função administrativa burocrática eram direcionadas pelo Sistema Estadual, portanto podem ser caracterizadas como tradicionais. Tradicional era também a disciplina rígida, que fazia parte do cotidiano escolar, conforme se pode verificar ainda no ano de 1971 pela listagem de compromissos que deveriam ser assumidos pelos alunos. Pressupõe-se que estes compromissos (deveres) eram divulgados aos alunos como primeira atividade do ano letivo, pois constavam na primeira página dos cadernos dos alunos ${ }^{2}$, o que leva a crer que à disciplina era dado elevado grau de importância.

1 - Assistir às aulas devidamente uniformizada;

2 - Observar fielmente o horário

3 - Assistir às aulas de religião, assistindo às quintas-feiras à Santa Missa.

4 - Acatar as instruções do Corpo Administrativo.

5 - Aceitar ordem e sugestões do corpo docente.

6 - Tomar parte em reuniões, festas, quaisquer atividades promovidas pela Escola.

7 - Não sair do Estabelecimento sem ordem prévia.

8 - Não permanecer na porta de entrada, nem nos corredores.

9 - Não usar de meios fraudulentos na execução de exames, provas, exercícios sujeitos a julgamento, considerando tais recursos incompatíveis com a dignidade escolar. (Caderno da aluna Elvi Foggiato, $3^{\circ} a n o-$ Escola Normal, 1971) (grifo no original)

Esta ação se apresenta como tipicamente tradicional, e com forte influência da Igreja Católica, que desempenhava papel moralizante visando a

Material escolar individual utilizado pelos alunos para anotações dos conteúdos escolares. 
manutenção da ordem social. Mas também influenciada pelo regime autoritário do governo militar, que objetivava a manutenção da ordem, caracterizado pela Política de Segurança Nacional.

Em relação às questões pedagógicas, entre elas a metodologia dos professores, principalmente, o que ficou evidenciado foi que, no período em que o Serviço do Ensino Normal era o setor que respondia pelo Magistério na Secretaria de Educação, a grande preocupação deste era colocar em prática um ensino cada vez melhor, e para isso eram promovidas reuniões no Setor e incentivada a presença dos professores, mas também a realização destas nas Escolas.

O principal foco dado para esta melhoria do ensino era a troca de experiências entre os professores das diferentes escolas Ao solicitar à ex-diretora Professora Lya, esclarecimento sobre esse fato, esta relatou que em certa ocasião esteve numa escola localizada na Colônia Rio Grande, para ministrar aula às professoras sobre o uso da crase. Em outro momento, a Escola Normal visitou uma Escola em Antonina e esta posteriormente veio visitar a Escola Normal em São José. Este relato é indicativo do intercâmbio que havia entre as escolas, cujo procedimento era sugerido pelo Serviço de Ensino Normal da Secretaria de Educação.

Essas ações sinalizam para ação pedagógica tipicamente da Pedagogia da Escola Nova e mais precisamente as idéias de Pilotto que enfatizava a escola como centro de divulgação da cultura.

É importante ressaltar que durante esse período as funções administrativas e pedagógicas eram concebidas como funções separadas, bem definidas, nas quais observa-se a presença da tendência tecnicista na educação.

\section{A Escola Normal e as demais Instituições Sociais do Município}

A Escola Normal mantinha relações amigáveis, de bom entrosamento e de parceria com as demais instituições sociais do Município. Os eventos promovidos pela Escola eram amplamente divulgados e bem aceitos pela comunidade em geral. A Escola promovia desfiles cívicos, solenidades de formatura, bailes, excursões educativo-recreativas, mas também participava em eventos promovidos por outras escolas locais e principalmente os promovidos pelas escolas primárias. Estava presente nos eventos da Igreja, com a qual manteve fortes relações, e em solenidades ou atos oficiais promovidos pela Prefeitura Municipal. 


\section{Considerações Finais}

A Escola Normal Colegial Estadual Henrique Pestalozzi, no decorrer de sua história, percorreu um caminho com características que foram comuns às demais Escolas Normais, no contexto amplo, porém, esta se constituiu por certas singularidades que foram construídas no seu próprio local de trabalho influenciando e sendo influenciada pela sua realidade local, ou seja, o Município de São José dos Pinhais.

Analisando a trajetória desta Escola, constatou-se que o processo de desenvolvimento de suas atividades escolares deu-se sempre acompanhando os movimentos da organização social, em nível local, mas também estadual e nacional. Isso vale também em relação à legislação, à qual a Escola esteve submetida durante o seu funcionamento. Mesmo durante a vigência de uma determinada lei, percebeu-se que a atuação da Escola já tendia a aderir a idéias novas.

A Escola Normal Henrique Pestalozzi funcionou no período de 1956 a 1979 sob a vigência da Lei Orgânica do Ensino Normal, (1946) e da Lei de Diretrizes e Bases da Educação Nacional, Lei 4024/61. Embora em 1977 já tivesse sido implantada a Lei 5692, de agosto de 1971, nos demais níveis de ensino no Município de forma gradativa, a Escola Normal Henrique Pestalozzi não funcionava de acordo com essa Lei e continuou executando suas práticas em consonância com a lei de 1961.

Com relação aos fatores que contribuíram para a criação e funcionamento da Escola Normal em São José dos Pinhais no período, os aspectos estudados informaram que um dos fatores fortemente determinante foi, sem dúvida, o da política mais ampla, não educacional. O que corroborou para esta afirmação foi o fato da escola ter sido criada em 1954 e permanecer dois anos sem ser instalada por falta de alunos. Além disso, em 1956, foi Chefe do Gabinete da Secretaria de Educação e Cultura, o professor Narciso Mendes e ainda há a considerar o fato do Sr. Ernesto Moro Redeschi, cidadão de São José, ter sido eleito Deputado Estadual pelo PSD, partido do governador Moisés Lupion, cujo cenário político favoreceu a criação e instalação da Escola.

Pode-se afirmar que as políticas educacionais interferiram no funcionamento da escola, porém não totalmente. Isto se explica pelo fato da Escola Normal ter funcionado de 1956 a 1962 de acordo com a Lei Orgânica do Ensino Normal; e a partir de 1962, até o encerramento de suas atividades em 1979, sob a vigência da Lei 4024/61, mesmo que já tivesse sido implantada no Município a Lei 5692/71, que era gradativa e foi iniciada em 1973, teoricamente, em 1977 já deveria ter sido implantada na Escola Normal.

No que diz respeito à política ampla (não educacional), local, nacional e também internacional, esta influenciou o funcionamento da Escola Normal, 
pois não havia naquele momento interesse em investir numa escola cuja estrutura de currículo já não era necessária ao tipo de sociedade que estava se implantando no País. E São José inseria-se naquele momento na economia paranaense e nacional, com a instalação de empresas, incluindo as multinacionais.

Apesar da expansão do ensino primário, da demanda social pela educação, a estrutura e organização do curso de formação de professores na Escola Normal não se coadunava com o modelo proposto na Lei 5692/71, pois se sabe que a Escola permaneceu com sua atuação voltada aos ditames da antiga, Lei 4024/61.

Outro fator pode ter sido a resistência da própria escola em aceitar uma proposta de estrutura de curso que extinguia a característica substancial do mesmo, quando a Lei 5692/71 transformou a Escola Normal numa habilitação de $2 .^{\circ} \mathrm{Grau}$, extinguido a profissionalização antes ofertada nas Escolas Normais de 2. ${ }^{\circ}$ Ciclo. Essa resistência permaneceu até ter sido decretada a cessação das atividades das escolas que funcionavam sob a vigência da Lei anterior, ou seja, da 4024/61.

Embora não se adequando à Lei 5692/71, a Escola Normal Henrique Pestalozzi sofreu a influência dos ditames da mesma, à medida que se modificavam as relações sociais de produção e São José dos Pinhais ingressava no novo mercado de trabalho. No entanto, o estudo mostrou que a presença da Escola Normal Henrique Pestalozzi foi marcante nas práticas pedagógicas da formação dos professores, convivendo ainda com a Pedagogia Tradicional. Quanto aos objetivos, eles foram atingidos, uma vez que se conseguiu resgatar nesta trajetória o modo de funcionamento, que foi próprio desta Escola Normal e que influenciou, sem dúvida, a Educação do Município de modo positivo, participando ativamente da história da educação de São José dos Pinhais, com marcas impressas com as características de uma Escola que promoveu uma formação de professores consistente e humanizadora.

\section{Referências}

DECRETO-LEI n. 8.530 de 2 de janeiro de 1946. Lei Orgânica do Ensino Normal. Rio de Janeiro, RJ: 2 de janeiro 125 de Independência de 58. da República. Disponível em http:// www.soleis.adv.br>. Acesso em: 20 fev. 2003.

LEI n. 4024 de 20 de dezembro de 1961. Fixa as Diretrizes e Bases da Educação Nacional. Diário Oficial da União. Brasília, DF, 20 dez. 1961.

LEI n. 5692 de 11 de agosto de 1971. Fixa Diretrizes e Bases para o Ensino de $1 .^{\circ}$ e $2 .^{\circ}$ Graus e dá outras providências. Diário Oficial da União. Brasília, DF: 11 ago. 1971. 
COLÉGIO Estadual Costa Viana. ARQUIVO. Escola Normal Henrique Pestalozzi. Circulares, Avisos e Instruções 59/60: Serviço do Ensino Normal: Circulares n. 14/56; 13/59; 15/59,s/d ; 20/59 ; 22 s/d ; 25/59; 36/59; 48/59s/d); 52/59 3/60). Ofício de 31/07/59; 26/ 05/59 Maria Carolina Delay. São José dos Pinhais, 2003 $-2004$. 1958-1979.

. Livro de relatório anual de notas de alunos. São José dos Pinhais,

COLNAGHI, M. C.; MAGALHÃES FILHO, F. de B. B. de; MAGALHÃES, M. D. B de. São José dos Pinhais: a trajetória de uma cidade. Curitiba: Prephacio, 1992.

CORDEIRO, A. Escola Normal Colegial Estadual Henrique Pestalozz. São José dos Pinhais. Depoimento oral concedido a Maria Lúcia Bassa Zem, 27 jan. 2004.

GALANTE, F. C. Escola Normal Colegial Estadual Henrique Pestalozz. São José dos Pinhais. Depoimento oral concedido a Maria Lúcia Bassa Zem, 9 fev. 2004.

GRACZYK, L. V. Escola Normal Colegial Estadual Henrique Pestalozz. São José dos Pinhais. Depoimento oral concedido a Maria Lúcia Bassa Zem, 1 out. 2004.

ESCOLA Normal Colegial Henrique Pestalozzi. Caderno do $3 .^{\circ}$ ano da aluna Elvi Foggiato. São José dos Pinhais, 1971.

MEIHY BOM, J. C. S. Manual de história oral. 4 ed. São Paulo, SP: Loyola, 2001. MIGUEL, M. E. B. A formação do professor e a organização social do trabalho. Curitiba: Editora da UFPR, 1997.

PARANÁ, Lei 10-54 de 21 de janeiro de 1954. Cria a Escola Normal Secundária na cidade de São José dos Pinhais. Diário Oficial do Estado do Paraná. Curitiba, n. 278, 20 fev. 1954. 